Süleyman Demirel Üniversitesi Fen Edebiyat Fakültesi Fen Dergisi

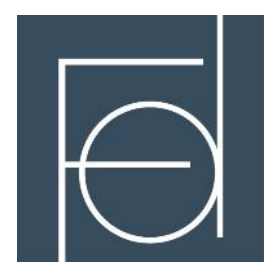

Süleyman Demirel University Faculty of Arts and Sciences Journal of Science

2021, 16(1): 271-278

DOI: $10.29233 /$ sdufeffd.925279

Atıf için / For Citation: E. Tel, B. Ünal, H. Şahan "Bazı yarı deneysel formüller kullanılarak 14.5 MeV civarında Kalay izotoplarının (n,p) nükleer reaksiyonların tesir kesitlerinin hesaplanması", Süleyman Demirel Üniversitesi Fen Edebiyat Fakültesi Fen Dergisi, 16(1), 271-278, 2021.

\title{
Bazı Yarı Deneysel Formüller Kullanılarak 14.5 MeV Civarında Kalay İzotoplarının (n,p) Nükleer Reaksiyonların Tesir Kesitlerinin Hesaplanması
}

\author{
Eyyup TEL ${ }^{1}$, Bülent ÜNAL ${ }^{1}$, Halide ŞAHAN ${ }^{* 1}$ \\ ${ }^{I}$ Osmaniye Korkut Ata Üniversitesi, Fen Edebiyat Fakültesi, Fizik Bölümü, 80000, Osmaniye, Türkiye \\ *yazlşllan yazar e-posta: halidesahan@osmaniye.edu.tr
}

(Alinış / Received: 21.04.2021, Kabul / Accepted: 18.05.2021, Yayımlanma / Published: 27.05.2021)

Özet: Fisyon ve füzyon reaktörlerinin güvenliğinin sağlanabilmesi için kullanılan malzeme ile parçacıklar arasındaki gerçekleşebilecek tüm etkileşimlerin göz önüne alınması gerekmektedir. Nükleer reaksiyonlara ait tesir kesiti verileri; radyoizotop üretimi, radyasyon zırhlama ve malzeme geliştirme çalışmaları olmak üzere oldukça geniş bir alanda kullanılmaktadır. Bu çalışmada, günümüz teknolojilerinde pek çok alanda kaplama malzemesi olarak kullanılan kalay elementinin füzyon reaktörlerinin zırhlamalarına ait nötronik radyasyon etkileri araştırılmıştır. ${ }^{112-124} \mathrm{Sn}$ hedef çekirdek izotopları için $14.5 \mathrm{MeV}$ yüksek gelme enerjili nötronlarla oluşturulan $(n, p)$ reaksiyonlarına ait tesir kesitleri literatürdeki yeni geliştirilmiş yarı deneysel formüller kullanılarak hesaplanmıştır. Yarı ampirik teorik formüllerden hesaplanan sonuçlar, EXFOR'dan elde edilen deneysel sonuçlar ile karşılaştırılmıştır.

Anahtar kelimeler: Kalay elementi, (n,p) reaksiyon, Zırhlama, Nötron, Tesir kesiti

\section{Cross Section Calculations of (n,p) Nuclear Reactions on Tin Isotopes Around 14.5 MeV Using Some Semi-Experimental Formulae}

\begin{abstract}
In order to ensure the safety of fission and fusion reactors, all interactions that may occur between the material used and the particles should be considered. Cross section data of nuclear reactions; are used in a wide range such as radio isotope production, radiation shielding and material development studies. In this study, the neutronic radiation effects of the tin element, which is used as a coating material in many areas in today's technologies, on the shielding of fusion reactors were been investigated. The $(n, p)$ reactions cross sections generated with $14.5 \mathrm{MeV}$ high incident energy neutrons for ${ }^{112-124} \mathrm{Sn}$ target core isotopes were calculated using newly developed semi-empirical formulae in the literature. The results calculated from the semi-empirical formulas were compared with the experimental results obtained from the EXFOR.
\end{abstract}

Key words: Tin element, (n,p) reaction, Shielding, Neutron, Cross section

\section{Giriş}

Karakteristik olarak soluk ve sarı bir tonu olan gümüşi bir metal olan kalay elementi doğada en sik rastlanan elementlerin başında gelmektedir. Peryodik tabloda 4A grubunda yer alan kalay elementi (Sn-50), korozyona dayanıklı gümüşi, yumuşak ve esnek bir metaldir. En çok $\mathrm{SnO}_{2}$ bileşiğinin yüksek sicaklıkta kömürle indirgenme reaksiyonları sonucunda elde edilen ve yaklaşık 3000 yıldan beri Bronz (Tunç) 
biçiminde kullanılan kalay elementinin işlenebilirliği, düşük ergime sıcaklı̆̆ yumuşaklığı, korozyona dayanaklılığı, zehirsiz olması, sürtünmeye dayanaklılığ 1 ve görünüşü kullanılmasına sebep olmaktadır. Kalay elementinin atom numarası 50 olup düşük erime sıcaklığına $\left(232{ }^{\circ} \mathrm{C}\right)$ sahip olduğu için kolaylıkla şekil verilebilmekle birlikte füzyon reaktörlerinde zırhlama malzemesi olarak kullanılmaktır. Saf kalay katılaştığında ise çoğu metal gibi ayna benzeri bir görünüm sağlar. Kalay elementinin doğal izotopları ve bolluk oranları sirasıyla ${ }^{112} \mathrm{Sn}(\% 0.97),{ }^{114} \mathrm{Sn}(\% 0.65),{ }^{115} \mathrm{Sn}(\% 0.36)$, ${ }^{116} \mathrm{Sn}(\% 14.53), \quad{ }^{117} \mathrm{Sn}(\% 7.68), \quad{ }^{118} \mathrm{Sn}(\% 24.22), \quad{ }^{119} \mathrm{Sn}(\% 8.58), \quad{ }^{120} \mathrm{Sn}(\% 32.59)$, ${ }^{122} \mathrm{Sn}(\% 4.63),{ }^{124} \mathrm{Sn}(\% 5.79)$ olarak verilebilir [1].

$\mathrm{Bu}$ çalışmada füzyon reaktörlerinde kaplama malzemesi olarak kullanılan kalay (Sn) elementi izotoplarının, $14.5 \mathrm{MeV}$ enerji aralığındaki yüksek enerjili nötronlar ile (n,p) reaksiyonlarının tesir kesitlerinin, EXFOR'dan [2] elde edilen deneysel sonuçlar ile yarı ampirik formüllerden elde edilen sonuçlar karşılaştırılarak uygunluğu test edilecektir.

\section{Materyal ve Metot}

Nükleer reaksiyonlarda füzyon reaktörlerinin tasarlanması ve yapımı aşamasında tesir kesitlerinin önemi büyüktür. Araştırma geliştirme çalışmalarının odak noktası bu etkiyi anlamak, özel bileşenleri ve mikro yapıları geliştirme aşamasında kullanmak ve uygun malzemeyi üretmektir [3-6].

$\mathrm{Bu}$ çalışmada $14.5 \mathrm{MeV}$ nötron enerjilerinde kalay izotoplarının $\left({ }^{112-124} \mathrm{Sn}\right)(\mathrm{n}, \mathrm{p})$ için bazı yarı ampirik tesir kesit formülleri kullanılmıştır. Farklı yazarlar tarafından sistematik olarak geliştirlen bu formüller Tel ve ark. (2003) [7], Levkovskii (1964) [8], Kumabe ve Fukuda (1987) [9], Konno ve ark. (1993) [10], Kasugai ve ark. (1995) [11], Ait-Tahar (1987) [12], Doczi ve ark. (1997) [13], tarafından geliştirilmiş ve Tablo 1'de verilmiş̧ir. Tablo 1'de Tel ve ark.(2003) [7] formülleri, değerlendirmeler yapılırken karışıklık olmaması açısından Tel ve ark. (2003) (I) [7] ve Tel ve ark.2 (2003) (II) [7] olarak gösterilmiştir. Tablo 1'deki birinci sütun (n,p) kesitler için yarı ampirik formüller öneren yazar isimlerini vermektedir. Birinci sütunda verilen yazarlara göre yarı ampirik formüller ikinci sütunda ve kütle aralıkları ikiüçüncüci sütunda verilmiştir. Tablo 1'de görüldüğü gibi yarı ampirik tesir kesiti formüller hedef çekirdeğin $Z, N$ ve A değerlerine bağlıdır.

\section{Bulgular}

Bu çalışmada $14.5 \mathrm{MeV}$ civarında kalay izotoplarının $\left({ }^{112-124} \mathrm{Sn}\right)$ yarı ampirik (n,p) tesir kesitlerini hesaplamak için literatürden elde edilen yarı ampirik formüller (Tablo 1) kullanılmıştır. Hesaplama sonucunda elde edilien tesir kesit sonuçları Tablo 2'de verilmiştir. Tesir kesit verileri milibarn $(\mathrm{mb})$ biriminde ifade edilmiștir. Teorik olarak hesaplanan yarı ampirik sonuçları EXFOR (Experimental Nuclear Reaction Data) [2] elde edilen deneysel sonuçlar ile karşılaştırılmıştır. EXFOR'den alınan 14-15 MeV civarındaki deneysel veriler Tablo 2'de son sütunda verilmiştir.

Tablo 2'de verilen 14.5 MeV civarındaki kalay elementinin 13 tane izotopu için yarı ampirik tesir kesit sonuçları kullanılarak Şekil 1'deki grafik elde edilmiştir. Tesir kesit değerlerinin her biri farklı renklerde sütünlar şeklindedir. Tablo 1 ve Şekil 1'den görüldüğü gibi $14.5 \mathrm{MeV}$ civarında tüm yarı ampirik formüller için en yüksek tesir kesit değerleri ${ }^{112} \mathrm{Sn}$ izotopunu (kırmızı renk) için elde edilmiştir. ${ }^{112} \mathrm{Sn}$ izotopundan sonra sirasıyla ${ }^{113} \mathrm{Sn}$ (pembe renk), ${ }^{114} \mathrm{Sn}$ (sarı renk), ${ }^{115} \mathrm{Sn}$ (gri renk), ${ }^{116} \mathrm{Sn}$ (mavi renk), ${ }^{117} \mathrm{Sn}$ (yeşil renk), ${ }^{118} \mathrm{Sn}$ (siyah renk), ${ }^{119} \mathrm{Sn}$ (açık mavi renk), ${ }^{120} \mathrm{Sn}$ (koyu yeşil renk), ${ }^{121} \mathrm{Sn}$ 
(mor renk), ${ }^{122} \mathrm{Sn}$ (zeytin yeşili renk), ${ }^{123} \mathrm{Sn}$ (turuncu renk) ve ${ }^{124} \mathrm{Sn}$ (gök mavisi renk) olarak düzgün olarak azaldığı görülmektedir. Sadece ${ }^{122} \mathrm{Sn}(15.94 \mathrm{mb})$ ve ${ }^{124} \mathrm{Sn}$ (17.33mb) izotopları için Kasugai ve ark. (1995) [11] formülünden hesaplanan değerlerinde diğerlerine göre biraz yükselme olduğu görülmektedir. Aşağıda her izotop için hesaplanan tesir kesit değerleri kısaca özetlenmiştir.

Tablo 1. Literatürden elde edilen (n, p) ) reaksiyon tesir kesit hesaplamak için kullanılan yarı ampirik formüller

\begin{tabular}{|c|c|c|}
\hline Yazar & $\begin{array}{c}\text { Formül } \\
\sigma(n, p)(\mathbf{m b}) \\
\end{array}$ & $\begin{array}{c}\text { Küitle } \\
\text { Aralığı }\end{array}$ \\
\hline Tel ve ark. (2003)(I) [7] & $14.56\left(\mathrm{~A}^{1 / 3}+1\right)^{2} \exp [-26.58(\mathrm{~N}-\mathrm{Z}) / \mathrm{A}]$ & $17 \leq \mathrm{A} \leq 239$ \\
\hline Tel ve ark. 2 (2003) (II) [7] & $\begin{array}{l}16.33\left(\mathrm{~A}^{1 / 3}+1\right)^{2} \exp [-26.17(\mathrm{~N}-\mathrm{Z}) / \mathrm{A}] \\
9.71\left(\mathrm{~A}^{1 / 3}+1\right)^{2} \exp [-21.87(\mathrm{~N}-\mathrm{Z}) / \mathrm{A}] \\
7.31\left(\mathrm{~A}^{1 / 3}+1\right)^{2} \exp [-20.21(\mathrm{~N}-\mathrm{Z}) / \mathrm{A}] \\
45.2\left(\mathrm{~A}^{1 / 3}+1\right)^{2} \exp [-33(\mathrm{~N}-\mathrm{Z}) / \mathrm{A}]\end{array}$ & $\begin{array}{l}\text { Çift-Z, Çift }-\mathrm{N} \\
\text { Çift-Z, Tek-N } \\
\text { Tek- Z, Çift-N } \\
40 \leq \mathrm{A} \leq 208\end{array}$ \\
\hline Kumabe ve Fukuda (1987) [9] & $\begin{array}{l}21.84 \exp [-34(\mathrm{~N}-\mathrm{Z}) / \mathrm{A}] \\
0.79 \mathrm{~A}^{2} \exp [-43.2(\mathrm{~N}-\mathrm{Z}) / \mathrm{A}] \\
0.75 \mathrm{~A}^{2} \exp [-45.0(\mathrm{~N}-\mathrm{Z}) / \mathrm{A}]\end{array}$ & $\begin{array}{l}19 \leq \mathrm{A} \leq 62 \\
63 \leq \mathrm{A} \leq 89 \\
90 \leq \mathrm{A} \leq 160\end{array}$ \\
\hline Konno ve ark. (1993) [10] & $31.42\left(\mathrm{~A}^{1 / 3}+1\right)^{2} \exp [-29.07(\mathrm{~N}-\mathrm{Z}) / \mathrm{A}]$ & \\
\hline Kasugai ve ark. (1995) [11] & $1264(N-Z+1) \exp [-4663(N-Z+1 / A]$ & $28 \leq \mathrm{A} \leq 187$ \\
\hline Ait-Tahar (1987) [12] & $107.98\left(\mathrm{~A}^{1 / 3}+1\right)^{2} \exp [-36.749(\mathrm{~N}-\mathrm{Z}+1) / \mathrm{A}]$ & $40 \leq \mathrm{A} \leq 236$ \\
\hline Doczi ve ark. (1997) [13] & $18.12\left(\mathrm{~A}^{1 / 3}+1\right)^{2} \exp \left[-19.16(\mathrm{~N}-\mathrm{Z}) / \mathrm{A}+(\mathrm{N}-\mathrm{Z})^{2} / \mathrm{A}^{2}\right]$ & $28 \leq \mathrm{A} \leq 209$ \\
\hline
\end{tabular}

${ }^{112} \mathrm{Sn}$ izotopu için elde edilen tesir kesit değerleri sırasıyla Tel ve ark. (2003) (I) için $28.59 \mathrm{mb}$, Tel ve ark. (2003) (II) [7] için $33.50 \mathrm{mb}$, Levkovski (1964) [8] için 44.61 mb, Kumabe ve Fukuda (1987) [9] için 75.78 mb, Konno ve ark. (1993) [10] için 47.25 mb, Kasugai ve ark. (1995) [11] için $73.30 \mathrm{mb}$, Ait-Tahar (1987) [12] için $51.37 \mathrm{mb}$ ve Doczi ve ark. (1997) [13] için $63.23 \mathrm{mb}$ olarak elde edilmiştir. ${ }^{112} \mathrm{Sn}$ izotopu için EXFOR'dan 33.6 \pm 2.1 (Betak ve ark.(2005) [2] ve 37.7 $\pm 7 \mathrm{mb}$ (Gopych ve ark. 1987) (EXFOR) [2] olmak üzere iki tane deneysel veriye ulaş1lmıştır. Deneysel verilerin hata payları dikkate alınarak aralık genişletilirse Tel ve ark. (2003) (II) [7] formülü ile elde sonucunun iyi bir sonuç olduğu ve Kumabe ve Fukuda (1987) [9], Kasugai ve ark. (1995) [11] ve Doczi ve ark. (1997) [13] formülleri ile elde edilen sonuçların yüksek olduğu görülmektedir.

${ }^{112} \mathrm{Sn}$ izotopundan sonra en yüksek tesir kesit değerleri ${ }^{113} \mathrm{Sn}$ izotopu için elde edilmiştir. ${ }^{113} \mathrm{Sn}$ izotopu için elde edilen tesir kesit değerleri sırasıyla Tel ve ark. (2003) [7] (I) için 23.28mb, Tel ve ark. (2003) (II) [7] için 26.7mb, Levkovski (1964) [8] için $34.54 \mathrm{mb}$, Kumabe ve Fukuda (1987) [9] için 54.06 mb, Konno ve ark. (1993) [10] için 37.73 mb, Kasugai ve ark. (1995) [11] için 54.81mb, Ait-Tahar (1987) [12] için $38.72 \mathrm{mb}$ ve Doczi ve ark. (1997) [13] için $52.81 \mathrm{mb}$ olarak elde edilmiştir. ${ }^{113} \mathrm{Sn}$ izotopunun tesir kesitlerinin deneysel sonuçları bulunamamıştır.

${ }^{113} \mathrm{Sn}$ izotopu için elde edilen tesir kesit değerleri sırasıyla Tel ve ark. (2003) (I) için $23.28 \mathrm{mb}$, Tel ve ark. (2003) (II) [7] için 26.7mb, Levkovski (1964) [8] için $34.54 \mathrm{mb}$, Kumabe ve Fukuda (1987) [9] için 54.06 mb, Konno ve ark. (1993) [10] için 37.73 mb, Kasugai ve ark. (1995) [11] için 54.81mb, Ait-Tahar (1987) [12] için $38.72 \mathrm{mb}$ ve Doczi ve ark. (1997) [13] için $52.81 \mathrm{mb}$ olarak elde edilmiştir. ${ }^{113} \mathrm{Sn}$ izotopunun tesir kesitlerinin deneysel sonuçları bulunamamıştır.

${ }^{113} \mathrm{Sn}$ izotopu için elde edilen tesir kesit değerleri sırasıyla Tel ve ark. (2003) (I) için 23.28mb, Tel ve ark. (2003) (II) [7] için 26.7mb, Levkovski (1964) [8] için $34.54 \mathrm{mb}$, 
Kumabe ve Fukuda (1987) [9] için 54.06 mb, Konno ve ark. (1993) [10] için 37.73 mb, Kasugai ve ark. (1995) [11] için 54.81mb, Ait-Tahar (1987) [12] için $38.72 \mathrm{mb}$ ve Doczi ve ark. (1997) [13] için $52.81 \mathrm{mb}$ olarak elde edilmiştir. ${ }^{113} \mathrm{Sn}$ izotopunun tesir kesitlerinin deneysel sonuçları bulunamamıştır.

Tablo 2. Kalay izotoplarının 14.5 MeV civarındaki (n,p) reaksiyonları için yarı ampirik formüller kullanılarak hesaplanan sonuçları

\begin{tabular}{|c|c|c|c|c|c|c|c|c|c|}
\hline 离 & 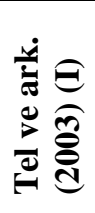 & 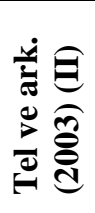 & 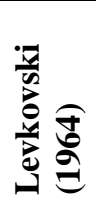 & 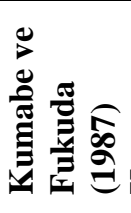 & 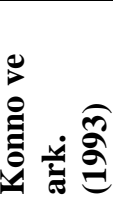 & 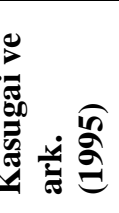 & 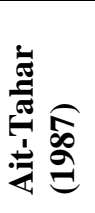 & 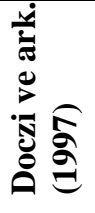 & $\underset{0}{a}$ \\
\hline${ }^{112} \mathrm{Sn}$ & 28.59 & 33.50 & 44.61 & 75.78 & 47.25 & 73.30 & 51.37 & 63.23 & $\begin{array}{c}33.6 \pm 2.1^{a} \\
37.7 \pm 7^{b}\end{array}$ \\
\hline${ }^{113} \mathrm{Sn}$ & 23.28 & 26.70 & 34.54 & 54.06 & 37.73 & 54.81 & 38.72 & 52.81 & - \\
\hline${ }^{114} \mathrm{Sn}$ & 19.04 & 22.45 & 26.86 & 38.79 & 30.26 & 41.04 & 29.34 & 44.14 & $20.5 \pm 1^{a}$ \\
\hline${ }^{115} \mathrm{Sn}$ & 15.62 & 19.25 & 20.99 & 28.01 & 24.36 & 30.78 & 22.33 & 36.93 & $35.2 \pm 2.6^{a}$ \\
\hline${ }^{116} \mathrm{Sn}$ & 12.86 & 15.26 & 16.46 & 20.34 & 19.68 & 23.13 & 17.08 & 30.93 & $\begin{array}{c}11 \pm 2^{c} \\
8 \pm 0.7^{d}\end{array}$ \\
\hline${ }^{117} \mathrm{Sn}$ & 10.62 & 14.04 & 12.97 & 14.85 & 15.96 & 17.43 & 13.13 & 25.93 & $\begin{array}{c}9.8 \pm 1.6^{e} \\
20 \pm 1.2^{f}\end{array}$ \\
\hline${ }^{118} \mathrm{Sn}$ & 8.80 & 10.51 & 10.26 & 10.90 & 12.99 & 13.17 & 10.13 & 21.75 & $\begin{array}{c}16 \pm 6^{g} \\
4.38 \pm 0.4^{h}\end{array}$ \\
\hline${ }^{119} \mathrm{Sn}$ & 7.32 & 10.35 & 8.15 & 8.05 & 10.61 & 13.86 & 7.86 & 18.27 & $\begin{array}{l}11.1 \pm 2.5^{i} \\
10.6 \pm 2.8^{i}\end{array}$ \\
\hline${ }^{120} \mathrm{Sn}$ & 6.10 & 7.33 & 6.50 & 5.97 & 8.69 & 14.56 & 6.12 & 15.36 & $\begin{array}{c}1.96 \pm 0.18^{h} \\
4.6 \pm 1.2^{i}\end{array}$ \\
\hline${ }^{121} \mathrm{Sn}$ & 5.10 & 7.71 & 5.20 & 4.45 & 7.15 & 5.78 & 4.78 & 12.93 & - \\
\hline${ }^{122} \mathrm{Sn}$ & 4.28 & 5.17 & 4.18 & 3.33 & 5.90 & 15.94 & 3.75 & 10.90 & - \\
\hline${ }^{123} \mathrm{Sn}$ & 3.60 & 5.80 & 3.37 & 2.51 & 4.88 & 3.39 & 2.96 & 9.19 & - \\
\hline${ }^{124} \mathrm{Sn}$ & 3.04 & 3.69 & 2.72 & 1.90 & 4.05 & 17.33 & 2.34 & 7.76 & - \\
\hline
\end{tabular}

${ }^{a}$ Betak ve ark.(2005), ${ }^{b}$ Gopych ve ark.(1987), ${ }^{c}$ Brzosko ve ark.(1965), ${ }^{d}$ Lulic ve ark.(1968), ${ }^{e}$ Lu ve ark.(1973), ${ }^{f}$ Grallert ve ark.(1993), ${ }^{g}$ Gopych ve ark.(1987) ${ }^{h}$ Lalremruata ve ark.(2012), ${ }^{i}$ Chursin ve ark.(1963) (Bunların tamamı EXFOR [2] verileridir)

Tablo 2 ve Şekil 1'deki verilere göre, ${ }^{114} \mathrm{Sn}$ izotopunun yüksek enerjili nötronlarla oluşturulan reaksiyonunun tesir kesitlerinin Tel ve ark. (2003) (I) için $19.04 \mathrm{mb}$, Tel ve ark. (2003) (II) [7] için $22.45 \mathrm{mb}$, Levkovski (1964) [8] için $26.86 \mathrm{mb}$, Kumabe ve Fukuda (1987) [9] için 38.79 mb, Konno ve ark. (1993) [10] için 30.26 mb, Kasugai ve ark. (1995) [11] için $41.04 \mathrm{mb}$, Ait-Tahar (1987) [12] için $29.34 \mathrm{mb}$ ve Doczi ve ark. (1997) [13] için 44.14 mb olarak elde edilmiştir.

Tablo 1 ile Şekil 1'deki verilere göre, ${ }^{115} \mathrm{Sn}$ izotopunun yüksek enerjili nötronlarla oluşturulan reaksiyonunun tesir kesitleri sırasıyla Tel ve ark. (2003) (I) için $15.62 \mathrm{mb}$, Tel ve ark. (2003) (II) [7] için 19.25 mb, Levkovski (1964) [8] için 20.99 mb, Kumabe ve Fukuda (1987) [9] için $28.01 \mathrm{mb}$, Konno ve ark. (1993) [10] için $24.36 \mathrm{mb}$, Kasugai ve ark. (1995) [11] için $30.78 \mathrm{mb}$, Ait-Tahar (1987) [12] için $22.33 \mathrm{mb}$ ve Doczi ve ark. (1997) [13] için $36.93 \mathrm{mb}$ olarak elde edilmiştir. EXFOR'dan ${ }^{115} \mathrm{Sn}$ izotopu için $35.2 \pm$ 2.6 (Betak ve ark.(2005) (EXFOR) [2] olmak üzere bir tane deneysel veriye ulaşılmıştır. Doczi ve ark. (1997) [13] formülü ile hesaplanan tesir kesiti, deneysel sonucun hata payı düşünülerek genişletildiğinde iyi sonuç olduğu görülmektedir. Tel ve ark. (2003) (I) [7] formülü ile elde edilen tesir kesit hesaplamasının deneysel veriye göre çok düşük olduğu görülmektedir. Kumabe ve Fukuda (1987) [9] ile Kasugai ve ark. (1995) [11] formüllerinin tesir kesit sonuçlarının yakın sonuçlar olduğu görülmektedir. 


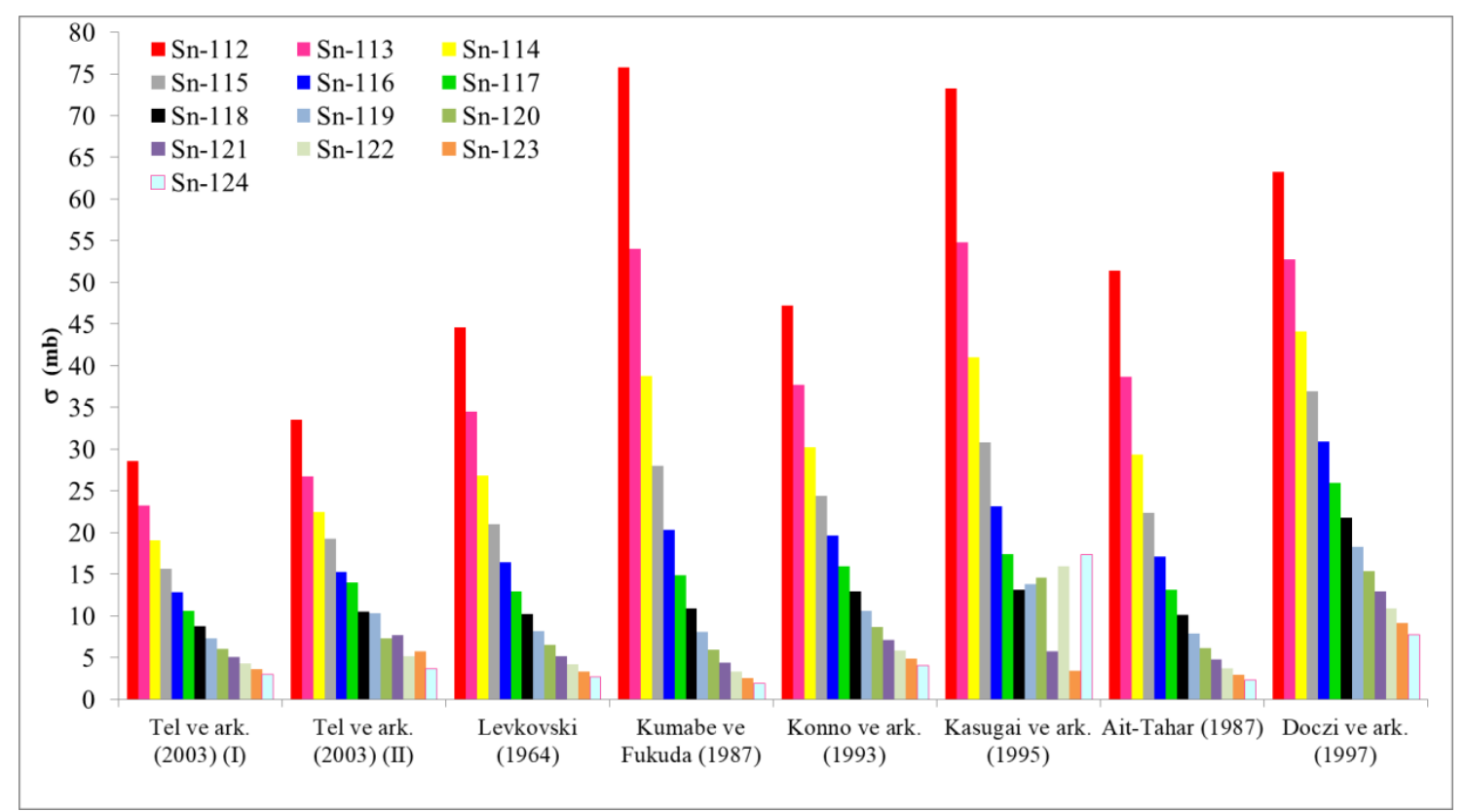

Şekil 1. Kalay izotoplarının 14-15 MeV civarındaki (n,p) reaksiyonları için yarı ampirik formüller kullanılarak hesaplanan sonuçları

${ }^{116} \mathrm{Sn}$ izotopu için tesir kesit değerleri sırasıyla Tel ve ark. (2003) (I) için $12.86 \mathrm{mb}$, Tel ve ark. (2003) (II) [7] için 15.26 mb, Levkovski (1964) [8] için 16.46 mb, Kumabe ve Fukuda (1987) [9] için 20.34 mb, Konno ve ark. (1993) [10] için 19.68 mb, Kasugai ve ark. (1995) [11] için $23.13 \mathrm{mb}$, Ait-Tahar (1987) [12] için $17.08 \mathrm{mb}$ ve Doczi ve ark. (1997) [13] için $30.93 \mathrm{mb}$ olarak elde edilmiştir. EXFOR'dan [2] ${ }^{116} \mathrm{Sn}$ izotopu için $11 \pm 2 \mathrm{mb}$ (Brzosko ve ark. 1965) [2] ve $8 \pm 0.7 \mathrm{mb}$ (Lulic ve ark. 1968) [2] olmak üzere iki tane deneysel veriye ulaşılmıştır. Deneysel verilerden elde edilen verilerin hata payları genişletildiğinde kendi aralarında iyi sonuçlar olduğu görülmektedir. Tel ve ark. (2003) (I) formülü ile elde edilen sonucun, deneysel verilerin hata payı düşünülerek genişletildiğinde çok iyi hesaplama olduğu görülmektedir. Doczi ve ark. (1997) [13] formülü ile elde edilen tesir kesitinin deneysel verilere göre yüksek olduğu görülmektedir.

Tablo 1 ile Şekil 1'deki verilere göre, ${ }^{117} \mathrm{Sn}$ izotopunun (n,p) reaksiyonunun tesir kesitleri sırasıyla Tel ve ark. (2003) (I) için $10.62 \mathrm{mb}$, Tel ve ark. (2003) (II) [7] için $14.04 \mathrm{mb}$, Levkovski (1964) [8] için 12.97 mb, Kumabe ve Fukuda (1987) [9] için 14.85 mb, Konno ve ark. (1993) [10] için 15.96 mb, Kasugai ve ark. (1995) [11] için $17.43 \mathrm{mb}$, Ait-Tahar (1987) [12] için $13.13 \mathrm{mb}$ ve Doczi ve ark. (1997) [13] için 25.93 $\mathrm{mb}$ olarak elde edilmiştir. EXFOR'dan ${ }^{115} \mathrm{Sn}$ izotopu için $35.2 \pm 2.6$ (Betak ve ark.(2005) (EXFOR) [2] olmak üzere bir tane deneysel veriye ulaşılmıştır. Doczi ve ark. (1997) [13] formülü ile hesaplanan tesir kesiti, deneysel sonucun hata pay1 düşünüelerek genişletildiğinde iyi sonuç olduğu görülmektedir. Tel ve ark. (2003) (I) [7] formülü ile elde edilen tesir kesit hesaplamasının deneysel veriye göre çok düşük olduğu görülmektedir. Kumabe ve Fukuda (1987) [9] ile Kasugai ve ark. (1995) [11] formüllerinin tesir kesit sonuçlarının yakın sonuçlar olduğu görülmektedir. EXFOR'dan [2] ${ }^{117} \mathrm{Sn}$ izotopu için $9.8 \pm 1.6 \mathrm{mb}$ (Lu ve ark. 1973) [2] ve $20 \pm 1.2$ (Grallert ve ark. 1993) olmak üzere iki tane deneysel veriye ulaş1lmıştır. Deneysel çalışmalarla elde edilen verilerin hata payları düşünülerek genişletildiğinde birbirlerinden farklı sonuçlar olduğu görülmektedir. Lu ve arkadaşlarından (1973) [2] elde edilen deneysel verinin hata payı düşünülerek genişletildiğinde Tel ve ark. (2003) [7] (I) formülü ile elde edilen hesaplamanın iyi bir sonuç olduğu görülmektedir. Doczi ve ark. (1997) [13] formülü ile 
elde edilen sonucun biraz farklı olduğu görülmektedir. Diğer formüller ile elde edilen sonuçların deneysel verilerin aralığında kaldığı görülmektedir.

${ }^{118}$ Sn izotopu için elde edilen (n,p) tesir kesit değerleri sırasıyla Tel ve ark. (2003) (I) için $8.8 \mathrm{mb}$, Tel ve ark. (2003) (II) [7] için $10.51 \mathrm{mb}$, Levkovski (1964) [8] için 10.26 mb, Kumabe ve Fukuda (1987) [9] için 10.9 mb, Konno ve ark. (1993) [10] için 12.99 mb, Kasugai ve ark. (1995) [11] için 13.17 mb, Ait-Tahar (1987) [12] için $10.13 \mathrm{mb}$ ve Doczi ve ark. (1997) [13] için $21.75 \mathrm{mb}$ olarak elde edilmiştir. ${ }^{113} \mathrm{Sn}$ izotopunun tesir kesitlerinin deneysel sonuçları bulunamamıştır. EXFOR'dan [2] 16 $\pm 6 \mathrm{mb}$ (Gopych ve ark. 1987) ve $4.38 \pm 0.4 \mathrm{mb}$ (Lalremruata ve ark. 2012) (EXFOR) [2] olmak üzere iki tane deneysel elde edilmiştir. Deneysel çalışmalarla elde edilen veriler hata payları düşünülerek genişletildiğinde birbirinden farklı veriler olduğu görülmektedir. Formüller ile elde edilen verilerin, deneysel çalışmalar ile elde edilen verilerin aralığında kalan değerler olduğu görülmektedir. Doczi ve ark. (1997) [13] formülü ile elde edilen sonucun deneysel verilerden daha yüksek olduğu görülmektedir.

${ }^{119} \mathrm{Sn}$ izotopu için elde edilen tesir kesit değerleri sırasıyla Tel ve ark. (2003) (I) için $7.32 \mathrm{mb}$, Tel ve ark. (2003) (II) [7] için $10.35 \mathrm{mb}$, Levkovski (1964) [8] için $8.15 \mathrm{mb}$, Kumabe ve Fukuda (1987) [9] için 8.05 mb, Konno ve ark. (1993) [10] için $10.61 \mathrm{mb}$, Kasugai ve ark. (1995) [11] için $13.86 \mathrm{mb}$, Ait-Tahar (1987) [12] için $7.86 \mathrm{mb}$ ve Doczi ve ark. (1997) [13] için $18.27 \mathrm{mb}$ olarak elde edilmiştir. ${ }^{113} \mathrm{Sn}$ izotopunun tesir kesitlerinin deneysel sonuçları bulunamamıştır. EXFOR'dan [2] $11.1 \pm 2.5 \mathrm{mb}$ ve $10.6 \pm 2.8 \mathrm{mb}$ (Chursin ve ark. 1963) olmak üzere iki tane deneysel elde edilmiştir. Deneysel çalışmalarla elde edilen verilerin hata payları düşünüldügünde kendi aralarında iyi sonuçlar olduğu görülmektedir. Deneysel verilerin hata payları düşünülerek genişletildiğinde Tel ve ark. (2003) (II) [5], Levkovski (1964) [8], Kumabe ve Fukuda (1987) [9], Konno ve ark. (1993) [10], Ait-Tahar (1987) [11] hesaplamalarının iyi sonuçlar olduğu görülmektedir. Doczi ve ark. (1997) [12] formülü ile elde edilen sonucun, deneysel verilerden daha yüksek olduğu görülmektedir.

${ }^{120} \mathrm{Sn}$ izotopu için hesaplanan (n,p) tesir kesit değerleri sırasıyla Tel ve ark. (2003) (I) için $6.1 \mathrm{mb}$, Tel ve ark. (2003) (II) [7] için $7.33 \mathrm{mb}$, Levkovski (1964) [8] için $6.5 \mathrm{mb}$, Kumabe ve Fukuda (1987) [9] için 5.97 mb, Konno ve ark. (1993) [10] için 8.69 mb, Kasugai ve ark. (1995) [11] için $14.56 \mathrm{mb}$, Ait-Tahar (1987) [12] için $6.12 \mathrm{mb}$ ve Doczi ve ark. (1997) [13] için $15.36 \mathrm{mb}$ olarak elde edilmiştir. EXFOR'dan [2] 1.96 \pm 0.18 (Lalremruata ve ark. 2012) ve $4.6 \pm 1.2 \mathrm{mb}$ (Chursin ve ark. 1963) olmak üzere iki tane deneysel elde edilmiştir. Deneysel çalışmalarda elde edilen veriler hata payları düşünülerek genişletildiğinde birbirine yakın sonuçlar olduğu görülmektedir. Deneysel sonuçların hata payları genişletilerek düşünüldüğünde Tel ve ark. (2003) (I), Tel ve ark. (2003) (II) [7], Levskovski (1964) [8], Kumabe ve Fukada (1987) [9], Ait-Tahar (1987) [12] formüllerinden elde edilen sonuçların deneysel sonuçlara yakın olduğu görülmektedir. Kasugai ve ark. (1995) [11] ve Doczi ve ark. (1997) [13] formülleri ile elde edilen sonuçların yüksek çıktığı görülmüştür.

${ }^{121} \mathrm{Sn}$ izotopu için yarı ampirik formüllerden hesaplanan $(\mathrm{n}, \mathrm{p})$ tesir kesit değerleri sırasiyla Tel ve ark. (2003) (I) için $5.1 \mathrm{mb}$, Tel ve ark. (2003) (II) [7] için $7.71 \mathrm{mb}$, Levkovski (1964) [8] için 5.2 mb, Kumabe ve Fukuda (1987) [9] için 4.45 mb, Konno ve ark. (1993) [10] için 7.15 mb, Kasugai ve ark. (1995) [11] için 5.78 mb, Ait-Tahar (1987) [12] için $4.78 \mathrm{mb}$ ve Doczi ve ark. (1997) [13] için $12.93 \mathrm{mb}$ olarak elde edilmiştir. ${ }^{121}$ Sn izotopunun tesir kesitlerinin deneysel sonuçları bulunamamıştır. Tel ve ark. (2003) (I) ve (II) [7], Levskovski (1964) [8], Kumabe ve Fukuda (1987) [9], Konno ve ark. (1995) [10], Kasugai ve ark. (1995) [11], Ait-Tahar (1987) [12] formüllerinden elde edilen hesaplamaların birbirine yakın sonuçlar olduğu görülmekle 
birlikte Doczi ve ark. (1997) [13] formülünden elde edilen tesir kesit değerinin yüksek çıktığ1 görülmektedir.

Tablo 1 ile Şekil 1'deki verilere göre, ${ }^{122}$ Sn izotopunun yüksek enerjili nötronlarla oluşturulan reaksiyonunun tesir kesitleri sırasıyla Tel ve ark. (2003) (I) için 4.28 mb, Tel ve ark. (2003) (II) [7] için 5.17 mb, Levkovski (1964) [8] için 4.17 mb, Kumabe ve Fukuda (1987) [9] için 3.33 mb, Konno ve ark. (1993) [10] için 5.9 mb, Kasugai ve ark. (1995) [11] için 15.94 mb, Ait-Tahar (1987) [12] için 3.75 mb ve Doczi ve ark. (1997) [13] için $10.9 \mathrm{mb}$ olarak elde edilmiştir. Tel ve ark. (2003) (I), Tel ve ark. (2003) (II) [7], Levskovski (1964) [8], Kumabe ve Fukada (1987) [9], Konno ve ark. (1993) [10], Ait-Tahar (1987) [12] formüllerinden elde edilen hesaplamaların birbirine yakın sonuçlar olduğu görülmekle birlikte Kasugai ve ark. (1995) [11] ve Doczi ve ark. (1997) [13] formüllerinden elde edilen tesir kesit değerlerinin daha yüksek olduğu görülmektedir. ${ }^{122} \mathrm{Sn}$ izotopunun tesir kesitlerinin deneysel sonuçları bulunamamıştır.

Tablo 2 ve Şekil 1 incelendiğinde ${ }^{123}$ Sn izotopu için elde edilen (n,p) tesir kesit değerleri sırasıyla Tel ve ark. (2003) (I) için $3.6 \mathrm{mb}$, Tel ve ark. (2003) (II) [7] için 5.8 mb, Levkovski (1964) [68] için 3.37 mb, Kumabe ve Fukuda (1987) [9] için $2.51 \mathrm{mb}$, Konno ve ark. (1993) [10] için 4.88 mb, Kasugai ve ark. (1995) [11] için 3.39 mb, AitTahar (1987) [12] için 2.96 mb ve Doczi ve ark. (1997) [13] için 9.19 mb olarak elde edilmiştir. ${ }^{123} \mathrm{Sn}$ izotopunun tesir kesitlerinin deneysel sonuçları bulunamamıştır. Tel ve ark. (2003) (I), Tel ve ark. (2003) (II) [7], Levskovski (1964) [8], Kumabe ve Fukuda (1987) [9], Konno ve ark. (1993) [10], Kasugai ve ark. (1995) [11], Ait-Tahar (1987) [12] formüllerinden elde edilen hesaplamaların birbirine yakın sonuçlar olduğu görülmekle birlikte Doczi ve ark. (1997) [13] formülünden elde edilen tesir kesit değerinin daha yüksek olduğu görülmektedir. ${ }^{123} \mathrm{Sn}$ izotopunun deneysel sonuçları bulunmadığ1 için tesir kesitleri olarak formüller ile elde edilen sonuçlar değerlendirilerek çalışmalar yürütülebilir.

Tablo 2 ve Şekil 1'deki verilere göre, ${ }^{124}$ Sn izotopu için elde edilen (n,p) tesir kesit değerleri sırasıyla Tel ve ark. (2003) (I) için $3.04 \mathrm{mb}$, Tel ve ark. (2003) (II) [7] için $3.69 \mathrm{mb}$, Levkovski (1964) [8] için $2.72 \mathrm{mb}$, Kumabe ve Fukuda (1987) [9] için 1.9 mb, Konno ve ark. (1993) [10] için 4.05 mb, Kasugai ve ark. (1995) [11] için 17.33 mb, Ait-Tahar (1987) [12] için $2.34 \mathrm{mb}$ ve Doczi ve ark. (1997) [13] için $7.76 \mathrm{mb}$ olarak elde edilmiştir. ${ }^{124} \mathrm{Sn}$ izotopunun tesir kesitlerinin deneysel sonuçları bulunamamıştır. Tel ve ark. (2003) (I), Tel ve ark. (2003) (II) [7], Levskovski (1964) [8], Kumabe ve Fukuda (1987) [9], Konno ve ark. (1993) [10], Ait-Tahar (1987) [12] formüllerinden elde edilen hesaplamaların birbirine yakın sonuçlar olduğu görülmektedir. Doczi ve ark. (1997) [13] formülünden elde edilen tesir kesit değerinin biraz farklı olduğu görülmekle birlikte Kasugai ve ark. (1995) [11] formülüyle yapılan hesaplamadan daha yüksek bir sonuç çıkmıştır.

\section{Sonuç ve Yorum}

Bu çalışmada literatürden Tel ve ark. (2003) (I ve II) [7], Levskovski (1964) [8], Kumabe ve Fukuda (1987) [9], Konno ve ark. (1993) [10], Ait-Tahar (1987) [12], Doczi ve ark. (1997) [13], Kasugai ve ark. (1995) [11] çalışmalarından elde edilen yarı ampirik tesir kesit formülleri kullanılarak kalay elementinin izotopları $\left({ }^{112-124} \mathrm{Sn}\right)$ için 14.5 MeV civarındaki yüksek gelme enerjili nötronlarla oluşturulan (n, p) reaksiyonlarına ait tesir kesitleri hesaplanmıştır. Elde edilen sonuçlar EXFOR [2] veri tabanından elde edilen deneysel sonuçları karşılaştırılmıştır. Elde edilen sonuçlar kısaca aşağıda belirtilmiştir. Literatürdeki tesir kesit formülleriyle yapılan hesaplamalar ile deneysel verilerden elde edilen sonuçların uyumlu olduğu görülmektedir. Kalay elementinin doğal izotoplarında $\left({ }^{122} \mathrm{Sn}\right.$ hariç) deneysel veriler olmakla birlikte uyumlu 
olduğu da görülmektedir. Doğal olmayan ${ }^{113} \mathrm{Sn},{ }^{121} \mathrm{Sn},{ }^{123} \mathrm{Sn},{ }^{124} \mathrm{Sn}$ izotoplarında ise deneysel verilere ulaşılamamıştır. Deneysel verileri olmayan kalay izotopları $\left({ }^{122} \mathrm{Sn},{ }^{113} \mathrm{Sn},{ }^{121} \mathrm{Sn},{ }^{123} \mathrm{Sn}\right)$ kaplama malzemesi olarak kullanılarak füzyon reaktörleri tasarımı yapılmak istendiğinde tesir kesit formüllerinden yararlanılabilir. Deneysel verilerin maliyetleri ve geçen süreler düşünüldüğünde, reaktör yapım çalışmalarında literatürdeki tesir kesit formülleri kullanılarak daha kolay ve ucuz tasarım yapılmasını sağlanabilir. Formüllerle elde edilen tesir kesitleri sonuçları kullanılarak makroskobik tesir kesitleri hesaplanmasına imkân sağlar.

\section{Araştırmacıların Katkı Oranı Beyanı}

Eyyup TEL: Araştırma, Veri iyileştirme, İnceleme ve Düzenleme Bülent ÜNAL: Kaynak, Materyal, Analiz, Araştırma, Veri Temini, Halide ŞAHAN: Orjinal Taslak Yazımı, İnceleme ve Düzenleme, Görselleştirme.

\section{Destek ve Teşekkür Beyanı}

Bu çalışma Osmaniye Korkut Ata Üniversitesi Bilimsel Araştırma Projeleri (BAP) Destekleme Programı tarafından desteklenmiştir. Proje numarası: OKÜBAP-2019-PT3-008.

\section{Çatışma Beyanı}

$\mathrm{Bu}$ çalışmanın yazarları olarak herhangi bir çatışma beyanımız bulunmadığını bildiririz.

\section{Etik Kurul Onayı ve Aydınlatılmış Onam Bilgileri}

$\mathrm{Bu}$ çalışmanın yazarları olarak herhangi bir etik kurul onayı ve/veya aydınlatılmış onam bilgileri beyanımız bulunmadığıı bildiririz.

\section{Kaynakça}

[1] M. S. Şadoğlu, "Nötral Kalayın Enerji Seviyeleri Üzerine İzotop Kayma Etkilerinin Hesaplanması", Sakarya Üniversitesi Fen Bilimleri Enstitüsü, Yüksek Lisans Tezi, Aksaray, 2, 2018.

[2] EXFOR/CSISRS: Erişim adresi: https://www.nndc.bnl.gov/exfor

[3] E. Tel, "Study on some structural fusion materials for (n,p) reactions up to $30 \mathrm{MeV}$ energy," $J$. Fusion. Energ., 29, 332-336, 2010.

[4] E. Tel, C. Durgu, N. N. Akt1, and Ş. Okuducu, "Calculations of excitation functions of some structural fusion materials for (n,t) reactions up to $50 \mathrm{MeV}$ energy," J. Fusion. Energ., 29, 290-294, 2010.

[5] M. Yigit and A. Kara, "Model-based predictions for nuclear excitation functions of neutron-induced reactions on 64,6668Zn targets," Nucl. Eng. Technol., 49, 996, 2017.

[6] A. Kara, T. Korkut, M. Yigit, and E. Tel, "Modelling study on production cross sections of 111In radioisotopes used in nuclear medicine," Kerntechnik, 80 (3), 270-274, 2015.

[7] E. Tel, B. Şarer, S.. Okuducu, A. Aydın, and G. Tanir, "A new empirical formula for 14-15 MeV neutron induced (n, p) reaction cross section," J. Phys. G: Nucl. Part. Phys. 29, 2169-2177, 2003.

[8] V. N. Levkovskii, "Empirical behavior of the (n, p) cross-section for 14-15 MeV neutrons," Soviet Phys. Jetp, 18, 213, 1964.

[9] I. Kumabe and K. Fukuda, "Empirical formulas for $14-\mathrm{MeV}$ (n, p) and (n, $\alpha)$ cross sections," $J$. Nucl. Sci. Technol., 24 (10), 839-843, 1987.

[10] C. Konno, Y Ikeda, K. Osihi, K. Kawede, H. Yamomoto, and H. Maekawa, Jaer1-1329, Japan Atomic Energy Research Institute, 1993.

[11] Y. Kasugai, Y. Ikeda, H. Yamamoto, and K. Kawade, "Systematics of activation cross-sections for 13.4-15.0 MeV neutrons," JAERI-Conf. 95-008, 1995.

[12] S. Ait Tahar, "The systematic of (n,p) cross section for $14 \mathrm{MeV}$ neutrons," Nucl. Phy., 13, 121-125, 1987.

[13] R. Doczi, V. Semkova, A. D. Majdeddin, Cs. M. Buczko, and J. Csikai, "Investigations on (n,p) cross sections in the $14 \mathrm{MeV}$ region," Indc (HUN)- 032, NDS, IAEA, 1997. 